\title{
Violence, stigma and psychiatric diagnosis: the effects of a history of violence on psychiatric diagnosis
}

\author{
AIMS AND METHOD \\ The aim of the study was to \\ investigate whether psychiatrists \\ consider that patients with \\ schizophrenia present a greater risk \\ of violence than patients with other \\ forms of mental illness. Two pairs of \\ clinical vignettes were devised. In \\ each pair, one contained a history of \\ violence and one did not. One \\ vignette was mailed to each of 2000 \\ consultant psychiatrists in the UK. \\ Respondents were asked to give a \\ preferred diagnosis. Rates of
}

diagnosis of bipolar disorder, schizoaffective disorder and schizophrenia were compared within vignette pairs.

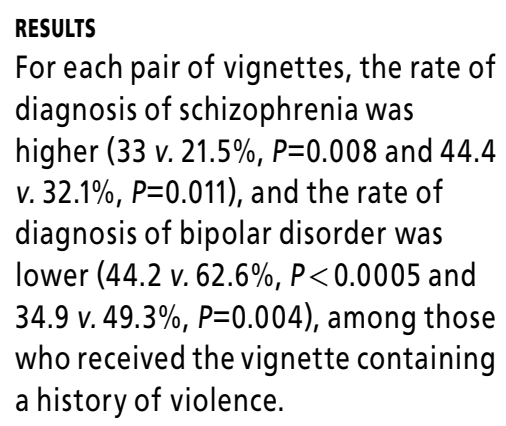

\author{
CLINICAL IMPLICATIONS \\ A history of violence may lead \\ to an increased likelihood \\ of receiving a diagnosis of \\ schizophrenia as opposed \\ to bipolar affective disorder. \\ This bias in diagnostic \\ decision-making may affect \\ the treatment received by a \\ patient and may perpetuate \\ and exacerbate the stigma \\ associated with a diagnosis \\ of schizophrenia.
}

The notion that people with mental illness are dangerous is as common and widespread (Pescosolido et al, 1999) as it is misplaced (Taylor \& Gunn, 1999; Walsh \& Fahy, 2002) and this is a major factor in the stigmatisation of those with mental illness by the public (James, 1998). Crisp et al (2000) demonstrated the prevalence of negative opinions about mental disorder among a sample of the British public. They considered that the most negative opinion was that people with mental disorder are dangerous and found that this was held most often about people with schizophrenia compared with other mental illness. Byrne (2000) argued that psychiatry itself bears some responsibility for maintaining stigmatisation, pointing to outdated theories of causation and treatment. It has been shown previously that psychiatrists hold stereotypes related to personality disorder (Lewis \& Appleby, 1988 ) and that racial stereotypes may influence diagnosis (Lewis et al, 1990; Minnis et al, 2001).

We wondered whether psychiatrists share a stereotype of the general public, regarding people with schizophrenia as more dangerous than those with other mental illnesses. If such a prejudice were clinically important, psychiatrists would be more likely to diagnose schizophrenia in a patient who had a history of being violent than in one without a violent history. Such a diagnostic bias would be important, in part because of the increased stigmatisation attached to a diagnosis of schizophrenia (Sartorius, 1998), but also in terms of ensuring diagnosis-appropriate treatment and support.

\section{Method}

We devised a clinical vignette of a patient with a diagnostically non-specific psychotic mental illness.

\begin{abstract}
A 27-year-old man presents as an emergency. He has never seen a psychiatrist before but his girlfriend believes that he was briefly given some tablets for his nerves by his general practitioner about 5 years ago. He has been well since. Over recent weeks his girlfriend has become increasingly concerned about his health. His sleep has been disturbed at night and he has begun to make odd comments. For example, he has said that he has large sums of money in an offshore bank account and that people are out to get him because of this. He can recognise his persecutors by the colour of their eyes and believes they are following him to the bank to rob him. He has stated that when he gets hold of his money he will use it to reduce poverty and hardship wherever he can find it. She cannot identify any precipitant for these changes but did comment that he was previously putting in a lot of hours at work.
\end{abstract}

We adapted the vignette to form two pairs. One pair related to domestic violence with the following varying sentence.

He has become increasingly argumentative with his girlfriend about these issues (vignette 1-nv).

He has become increasingly argumentative with his girlfriend about these issues and has pushed her and hit her on a few occasions (vignette $1-v$ ).

The second pair related to risk of violence to strangers and included the following varying sentence.

He has begun to take a circuitous route to the bank to avoid them (vignette 2-nv).

He has begun to carry a knife to protect himself and on one occasion grabbed a man in the street and threatened him (vignette 2-v).

In a pilot study, 5 of 14 respondents made a diagnosis of bipolar affective disorder for the violent vignette and 9 of 15 for the non-violent vignette. A power calculation showed that the study required a sample size of 84 to achieve $90 \%$ power at the $5 \%$ level.

The vignettes were mailed to a random sample of 2000 consultant psychiatrists taken from the member- 
Table 1. Sub-specialty of respondents

\begin{tabular}{|lrr|} 
& \multicolumn{2}{c}{ Respondents } \\
Sub-specialty & \multicolumn{2}{c}{$n(\%)$} \\
\hline General adult psychiatry & 425 & $(52.0)$ \\
Forensic psychiatry & 57 & $(7.0)$ \\
Child and adolescent psychiatry & 101 & $(12.3)$ \\
Psychiatry of learning disabilities & 47 & $(5.7)$ \\
Old age psychiatry & 138 & $(16.9)$ \\
Psychotherapy & 25 & $(3.1)$ \\
Substance misuse & 25 & $(3.1)$ \\
\hline
\end{tabular}

Table 2. Diagnosis according to gender of respondent

\begin{tabular}{|c|c|c|}
\hline \multirow[b]{2}{*}{ Diagnosis } & \multicolumn{2}{|c|}{$\begin{array}{c}\text { Respondents } \\
n(\%)\end{array}$} \\
\hline & $\begin{array}{c}\text { Male } \\
(n=544)\end{array}$ & $\begin{array}{l}\text { Female } \\
(n=274)\end{array}$ \\
\hline Schizophrenia ${ }^{1}$ & $190(34.9)$ & $75(27.4)$ \\
\hline Schizoaffective disorder ${ }^{2}$ & $108(19.9)$ & $51(18.6)$ \\
\hline Bipolar affective disorder ${ }^{3}$ & $246(45.2)$ & $148(54.0)$ \\
\hline \multicolumn{3}{|l|}{ 1. $\chi^{2}{ }_{1}=4.748, P=0.029$. } \\
\hline \multicolumn{3}{|l|}{ 2. $\chi_{1}^{2}=0.179, P=0.672$. } \\
\hline 3. $\chi^{2}{ }_{1}=5.644, P=0.018$. & & \\
\hline
\end{tabular}

ship list of the Royal College of Psychiatrists. Respondents were asked to rank the diagnoses schizophrenia, schizoaffective disorder and bipolar affective disorder in order of likelihood.

\section{Results}

Of the 2000 subjects, $41 \%(n=818)$ returned a completed questionnaire; $26.3 \%$ (214) had received vignette $1-n v$, $25.2 \%$ (206) had received vignette $1-v, 25.6 \%$ (209) had received vignette $2-n v$ and $23.1 \%$ (189) had received vignette $2-v$. The mean age of respondents was 46.41 years (range $31-77$ years, s.d. $=7.68$ ); $66.5 \%$ (544) of the respondents were male. The sub-specialities of respondents are shown in Table 1.

There was no significant difference in age of respondent $(F(3,812)=0.665, P=0.574)$, gender of respondent $\left(\chi_{3}^{2}=3.220, P=0.359\right)$ or sub-specialty of respondent $\left(\chi_{18}^{2}=25.976, P=0.1\right)$ for the four vignettes.

There was no significant difference in preferred diagnosis according to sub-specialty of respondent $\left(\chi_{12}^{2}=19.666, P=0.074\right)$ but there was a significant difference in diagnosis according to gender of respondent $\left(\chi_{2}^{2}=6.280, P=0.043\right.$; Table 2).

The mean age of those making a preferred diagnosis of bipolar affective disorder (45.19 years) was less than that for those diagnosing schizophrenia (46.60 years) and those diagnosing schizoaffective disorder (49.11 years). The difference between the groups was significant $(F(2,813)=15.414, P<0.0005)$. Tukey tests showed that all diagnostic groups were different from each other in terms of
Table 3. Preferred diagnosis of respondents for vignette pair 1 (domestic violence) ${ }^{1}$

\begin{tabular}{|cccc} 
& $\begin{array}{c}\text { Respon- } \\
\text { dents n (\%) }\end{array}$ & $\chi^{2}$ & $P$ \\
\hline $\begin{array}{l}\text { Schizophrenia } \\
\quad \text { Vignette 1-nv }\end{array}$ & $46(21.5)$ & & \\
$\quad$ Vignette 1-v & $68(33.0)$ & & 0.0037 \\
$\begin{array}{l}\text { Schizoaffective disorder } \\
\text { Vignette 1-nv }\end{array}$ & $34(15.9)$ & & \\
$\quad$ Vignette 1-v & $47(22.8)$ & 3.236 & 0.072 \\
$\begin{array}{l}\text { Bipolar affective disorder } \\
\text { Vignette 1-nv }\end{array}$ & $134(62.6)$ & & \\
$\quad$ Vignette 1-v & $91(44.2)$ & 14.353 & $<0.0005$ \\
\hline
\end{tabular}

original papers

$\mathrm{nv}$, non-violent; v, violent

1. A total of 214 respondents gave diagnosis for vignette $1-n v$ and 206 for vignette $1-\mathrm{v}$.

Table 4. Preferred diagnosis of respondents for vignette pair 2

(threatening a stranger with a weapon) ${ }^{1}$

\begin{tabular}{|c|c|c|c|}
\hline & $\begin{array}{c}\text { Respondents } \\
n(\%)\end{array}$ & $\chi^{2}$ & $P$ \\
\hline \multicolumn{4}{|l|}{ Schizophrenia } \\
\hline Vignette $2-n v$ & $67(32.1)$ & \multirow{2}{*}{6.468} & \multirow{2}{*}{0.011} \\
\hline Vignette $2-v$ & $84(44.4)$ & & \\
\hline \multicolumn{4}{|c|}{ Schizoaffective disorder } \\
\hline Vignette 2-nv & $39(18.7)$ & \multirow{2}{*}{0.246} & \multirow{2}{*}{0.620} \\
\hline Vignette $2-v$ & $39(20.6)$ & & \\
\hline \multicolumn{4}{|c|}{ Bipolar affective disorder } \\
\hline Vignette 2-nv & $103(49.3)$ & \multirow{2}{*}{8.379} & \multirow{2}{*}{0.004} \\
\hline Vignette $2-v$ & $66(34.9)$ & & \\
\hline
\end{tabular}

1. A total of 209 respondents gave a diagnosis for vignette $2-n v$ and 189 for vignette $2-v$.

age of psychiatrists making that diagnosis (schizophrenia $v$. bipolar affective disorder $P=0.049,95 \% \mathrm{Cl} 0.004-0.282$; schizoaffective disorder $v$. schizophrenia $P=0.003,95 \% \mathrm{Cl}$ $0.74-4.29$; schizoaffective disorder $v$. bipolar affective disorder $P<0.0005,95 \% \mathrm{Cl} 2.26-5.59$ ).

There was a significant difference in preferred diagnosis for the violent and non-violent vignette for both vignette pair $1\left(\chi_{2}^{2}=14.403, P=0.001\right)$ and vignette pair 2 $\left(\chi_{2}^{2}=9.032, P=0.011\right)$. Tables 3 and 4 compare frequencies of preferred diagnoses for each vignette.

\section{Discussion}

Psychiatrists who received the 'non-violent' vignette were significantly more likely to rate bipolar affective disorder and less likely to rate schizophrenia as the most likely diagnosis than those who received the 'violent' vignette. The results were the same for both pairs of vignettes and suggest that psychiatrists do tend to regard people with schizophrenia as being more violent than those with bipolar affective disorder, and this prejudice leads to a diagnostic bias.

The response rate was reasonable for a postal survey and provided sufficient power for the study according to 
our pilot. The use of two pairs of vignettes allowed investigation of the effects of different types of violence. Vignette pair 1 describes anger-mediated violence against original papers

a spouse, whereas vignette pair 2 describes violence related to perceived threat from a stranger. The observation that they were both rated similarly suggests that it is violence itself which leads to diagnostic bias rather than assumptions about the causes of violence, which may relate to psychopathology.

The diagnoses schizophrenia, schizoaffective disorder and bipolar affective disorder were chosen as alternatives because, despite current categorical classification, clinical practice commonly requires a subjective assessment of paramount symptoms, tending towards a dimensional framework. Schizophrenia is often considered to be associated with violence more commonly than affective disorder (Higgins, 1990), despite some recent evidence that this might not be the case (Hodgins et al, 1999; Monahan et al, 2001). However, neither ICD-10 (World Health Organization, 1992) nor DSM-IV (American Psychiatric Association, 1994) include risk of violence as a diagnostic criterion or make any statements about the relative risk of violence according to diagnosis. There was no significant difference in the proportions of respondents diagnosing schizoaffective disorder. It would be interesting to know whether the presence of a history of violence led to diagnoses changing on a continuum from bipolar affective disorder through schizoaffective disorder to schizophrenia.

The higher rate of diagnosis of schizophrenia for vignette pair 2 compared with pair 1 is probably a result of the varying sentence, which in pair 2 suggested more planning of actions in response to psychosis. This may have suggested that the persecutory ideas were of longer standing or more persistent than in pair 1, and tended to favour a diagnosis of schizophrenia.

It was noteworthy that the mean age of respondents was higher for those who diagnosed schizoaffective disorder than for those who diagnosed schizophrenia, and this in turn was higher than for those who diagnosed bipolar affective disorder. This may reflect differences in training or may suggest that diagnostic preferences of individuals change over time. There was no difference in mean age for diagnosis given according to vignette, so this would not account for the observed effect of violence on diagnosis The observation that a greater proportion of male respondents diagnosed schizophrenia and a greater proportion of female respondents diagnosed bipolar affective disorder is interesting but the current study does not allow further investigation of this.

Psychiatric diagnosis, being syndrome based and lacking objective investigations which confirm or exclude diagnoses, is particularly vulnerable to prejudice and bias. Diagnostic fidelity is of great importance. The misattribution of syndromal diagnoses may lead to a patient receiving less effective treatment and less appropriate education about their illness. Misdiagnosis is liable to perpetuate prejudice against and exacerbate stigmatisation of people with schizophrenia. The prognoses of the three disorders are different. This may be of particular importance for those who have committed violent offences, influencing the likelihood of receiving an indefinite restriction order (Section 41 of the Mental Health Act 1983) or the level of security of accommodation to which they are admitted.

In recent years both the World Health Organization (Sartorius, 1998) and the Royal College of Psychiatrists (Crisp, 1999) have launched campaigns to tackle stigmatisation of those with mental illness by the public and to reduce this cause of additional disability. Perhaps it is time for more attention to be focused on the prejudices held by psychiatrists.

\section{Declaration of interest}

None.

\section{Acknowledgement}

The authors are grateful to Dr Sayeed Haque for statistical advice.

\section{References}

AMERICAN PSYCHIATRIC

ASSOCIATION (1994) Diagnostic and

Statistical Manual of Mental Disorders (4th edn) (DSM-IV). Washington, DC APA.

BYRNE, P. (2000) Stigma of mental illness and ways of diminishing it. Advances in Psychiatric Treatment, 6 , 65-72.

CRISP, A. H. (1999) The stigmatization of sufferers with mental disorders. British Journal of General Practice, 49 3-4.

CRISP, A. H., GELDER, M. G., RIX, S., et al (2000) Stigmatisation of people with mental illnesses. British Journal of Psychiatry, 177, 4-7.

HIGGINS, J. (1990) Affective psychoses. In Principles and Practice of Forensic Psychiatry (eds R. Bluglass \& P. Bowden), pp. 345-352. London: Churchill Livingstone.

HODGINS, S., LAPALME, M. \& TOUPIN, J. (1999) Criminal activities and substance use of patients with major affective disorders and schizophrenia: a 2 year follow up. Journal of Affective Disorders, 55, 187-202.

JAMES, A. (1998) Stigma of mental illness. Lancet, 352, 1048.

LEWIS, G. \& APPLEBY, L. (1988) Personality disorder: the patients psychiatrists dislike. British Journal of Psychiatry, 153, 44-49.

LEWIS, G., CROFT-JEFFREYS, C. \& DAVID, A. (1990) Are British psychiatrists racist? British Journal of Psychiatry, 157, 410-415.

MINNIS, H., McMILLAN, A., GILLIES, M., et al (2001) Racial stereotyping: survey of psychiatrists in the United Kingdom. BMJ, 323, 905-906.

MONAHAN, J., STEADMAN, H. J., SILVER, E., et al (2001) Rethinking Risk Assessment: the Macarthur Study of Mental Disorder and Violence. New York: Oxford University Press.

PESCOSOLIDO, B., MONAHAN, J., LINK, B. G., et al (1999) The public view of the competence, dangerousness and need for legal coercion among persons with mental illness. American Journal of Public Health, 89, 1339-1345.

SARTORIUS, N. (1998) Stigma: what can psychiatrists do about it? Lancet, 252, 1058-1059.

TAYLOR, P. J. \& GUNN, J. (1999) Homicides by people with mental illness: myth and reality. British Journal of Psychiatry, 174, 9-14.

WALSH, E. \& FAHY,T. (2002) Violence in society. BMJ, 325, 507-508.

WORLD HEALTH ORGANIZATION (1992) The ICD-10 Classification of Mental and Behavioural Disorders. Clinical Descriptions and Diagnostic Guidelines. Geneva:WHO.

*Tom Clark Consultant Forensic Psychiatrist and Honorary Senior Clinical Lecturer in Forensic Psychiatry, Reaside Clinic, Birmingham Great Park, Rubery, Birmingham B45 9BE, e-mail: thomas.clark@bsmht.nhs.uk, Renarta Rowe Specialist Registrar in Forensic Psychiatry, Reaside Clinic, Birmingham 